Journal of World Architecture

Research Article

\title{
Causes and Management of Concrete Cracks in Construction Engineering
}

Hui Lin*, Yufeng Zhang, Dezheng Qin

Shandong Jiaotong University, Jinan 250357, Shandong Province, China

\begin{abstract}
In today's comprehensive development of the domestic economy, China's construction industry has reaped remarkable achievements. As a very important composition in the field of construction in China, the characteristics of concrete engineering itself determines that it is prone to encounter a variety of problems, the most frequent of which is various cracks. Cracks not only affect the aesthetics of the building, but also affect the durability and safety of the project. Considering these potential hazards, the causes of concrete cracks must be carefully analyzed to control and improve them in an effective way to ensure the safety and stability of concrete buildings.
\end{abstract}

Keywords: Construction; Concrete; Cracking; Causes; Management

Publication date: September, 2020

Publication online: 30 September, 2020

*Corresponding author: Hui Lin, 1653279809@ qq.com

\section{Introduction}

Concrete cracks are the most common problem in construction projects, which seriously affects the service life and quality of buildings and attracts great attention from regional government departments. Many domestic engineers have joined the exploration process of the solution to the problem, the construction must be to protect the quality of materials as the first priority, the construction must strengthen supervision, good environmental temperature control, if the discovery of cracks, must be the first time to remedy, so as to avoid the problem becomes serious. The above practices are key to protecting the safety and stability of the building.

\section{Types of concrete cracks}

\subsection{Structural cracks}

The reason why there will be structural cracks in the construction of concrete works and the following several reasons are directly related. First of all, the design link did not do a good job of the structure of the bearing capacity of serious consideration, because the design is unreasonable, so it can not guarantee that the bearing capacity to meet the requirements. Secondly, many external factors will affect the project itself, such as the outside temperature is too low, but the concrete itself under the effect of hydrothermalization problems, the internal temperature is very high, this time there will be cracks, of course, if the outside temperature is too high, resulting in the structure of the surface temperature exceeds the internal temperature will also appear crack problem. Finally, because of substandard technology in construction, negligence in construction may also cause concrete cracks. Strict control of every construction detail and every construction process is the only way to prevent the appearance of cracking problems ${ }^{[1]}$.

\subsection{Non-structural cracks}

In concrete construction, humidity issues have a very obvious and significant impact on the project structure, and the result is shrinkage cracks. If the outside humidity is high, the concrete material is likely to react with the moisture in the environment and expand. After exposure to sunlight, the internal moisture evaporates and the concrete begins to shrink, resulting in cracking. During concrete construction, changes in humidity can also cause cracking problems. For example, the temperature difference between day and night in some areas is relatively large, and the change of weather during construction will directly lead to the change of temperature difference between inside and outside the concrete, which will lead to concrete cracks. During 
concrete construction, some projects have foundation settlement, so the concrete structure begins to misalign, then the concrete structure will crack due to pressure problems, affecting the safety of the entire building.

\section{Research on the causes of concrete cracking}

Based on the literature and the author's engineering experience, the causes of concrete cracking are related to the following conditions.

\subsection{Design reasons}

The first step in construction is design, and the design process requires geological surveys and data measurements, which are directly related to the design outcome. When designing the building structure, the design content is reasonable or not related to the final choice of concrete materials, the choice of engineering solutions. In addition, various objective factors such as temperature, climate, and geology have a direct impact on the design of the building. Computational theory is more or less related to effective design and the formation of cracks in concrete ${ }^{[2]}$.

\subsection{Concrete materials}

Project construction, the rational choice of materials is very important, concrete materials for coarse and fine aggregates and cement, of course, occasionally add some such as sand, steel, cement substances used to adjust the role of concrete. If the choice of materials is unreasonable, unscientific, it will lead to the effect of concrete projects can not achieve the desired goal. When selecting materials, determine the materials in strict accordance with the expected design results and requirements. It is necessary to use cement with standard stability and less alkaline aggregates. The material must have sufficient permeability and crack resistance. The material needs to be applied with good control of the mud content to avoid the project becoming a jerry-built project after completion.

\subsection{Environmental and material formulation reasons}

The physical laws of nature are thermal expansion and contraction, no matter what the material is more or less. Although concrete is a special material, it still cannot escape the laws of nature. Under the effect of thermal expansion and contraction, the temperature change stress of the concrete will then exceed its own control, and the result will be gaps. In the pouring part of the construction project, the area poured is large, so it will lead to the rapid diffusion of the outside temperature ${ }^{[3]}$. It is difficult to diffuse the internal temperature of the concrete, and on rainy days there will be problems with heat and humidity, which in turn will appear in the concrete, causing cracks. The preparation of building materials is very important when working on concrete projects. The proper water-cement ratio is related to whether the concrete will have pores and blisters. In many cases, guttation and disintegrate are directly related to the issue.

\subsection{Post-care}

After finishing the concrete pouring operation, the project must be cured the first time. Concrete pouring will have a relatively large temperature difference between inside and outside, after the completion of the project, the first time the temperature and humidity must be cured. It is assumed that the problem of temperature difference will cause concrete shrinkage, leading to cracks, which will directly affect the performance of the building and shorten the life of the building.

3.5 Construction process

The construction of concrete can cause concrete cracking problems if the construction process is backward and unreasonable. This is due to the fact that in many cases there are technical ability limitations of the construction personnel. The domestic construction industry has been developing rapidly, and as a result, there is a growing shortage of construction personnel with sufficient experience, and experienced personnel cannot be seen in many projects, which will naturally affect the quality of construction and cannot guarantee construction requirements. In many cases, in order to protect the construction schedule, construction units will usually recruit a large number of migrant workers, only a simple training to organize their entry into the construction site. The construction workers do not understand the characteristics and principles of the project, and do not understand the standard requirements of the system construction. Construction workers strictly follow the requirements of the foreman, and unreasonable and inadequate construction techniques are the norm. Concrete assembly, transport of components and pouring processes are not operated according to standards and regulations. Concrete cracks appear frequently in such a background. Some engineering units did not check the materials in place during construction, and process negligence was very common. Construction teams rarely conduct strict inspection of aggregates, sand and gravel as well as cement, and many inferior materials without certificates enter the site, which does not guarantee the quality of 
the project and causes many problems.

\section{Methods of manage concrete cracking}

\subsection{Strict control of concrete temperature}

Checking the temperature of concrete requires a focus on temperature control work, starting with the following points. The first step is to use conventional plastic of $0.14 \mathrm{~mm}$ thickness, covered with three layers of felt. Secondly, the existing aggregate grading situation is improved, in particular the amount of concrete cement can be adjusted by adding additives. In addition, when mixing concrete, the concrete temperature needs to be well controlled, the use of cooling water to achieve the desired effect of the project. Finally, in strict accordance with the provisions of the operation, demolition, insulation should be determined according to the current temperature conditions and engineering processes. Must focus on winter insulation work to protect the exposed thin wall.

\subsection{Refinement of design}

To prevent the problem of concrete cracking, more effort must be put into the design of the construction. It is necessary to design the pouring process carefully, especially when some construction sites are small and therefore cannot be mixed, so it is necessary to use concrete trucks to transport the concrete, and to keep mixing to avoid condensation. Careful planning of the concrete elements and the equipment to be used before pouring is necessary to avoid collision of equipment and elements after the pouring is finished.

\subsection{Rational adjustment of raw material ratios}

No matter what process is used, if there is a problem in the concrete raw material link, it will cause serious construction quality problems. In order to avoid pores and bubbles in the project, it is necessary to optimize the proportion of concrete raw materials. Strict control of the procurement process, with emphasis on checking the mud content and particle size. According to the construction site conditions and project requirements, fine-tune the concrete formula, add appropriate amount of water-reducing agent and flocculant to improve the performance of concrete, so that the concrete can be more suitable for the site environment.

\subsection{Rational proportioning to improve quality}

Concrete proportion will also affect the quality of the project, the proportion of reasonable choice is very important, including the sand content. Do a good job of cement dosage, water glue ratio management, to improve the final strength of concrete. Proportioning should be based on laboratory test results and the strength of the concrete itself to determine the full consideration of the site, especially the characteristics of the climate, good proportioning management.

\subsection{Careful protect}

After finishing pouring, the formed concrete must be cured immediately to prevent cracks in the concrete at a later stage. Especially in rainy weather, it is necessary to organize the use of rain protection to avoid the temperature change and dryness of the concrete. It is well known that concrete has its own guttation characteristics, so the main task is to prevent excessive temperature differences.

\section{Conclusion}

From the description in this paper, it can be seen that in order to ensure the quality of concrete projects and avoid the appearance of engineering cracks, it is crucial to strengthen the control of cracks. It should focus on the source to improve the durability and safety of the building itself. In today's technological advancement, there will be more ways to manage concrete cracks in the future to improve concrete quality and ensure concrete stability.

\section{References}

[1] Bai WL. Crack detection, evaluation and reinforcement of a cast-in-place concrete slab[J]. Building Structures, 2020, 50(13):24-29.

[2] Li YF, Liu T, Duan YH, et al. Study on the evolution mechanism of microcracking in calcium chloride solution of fly ashbased polymer concrete[J]. Brick Tile, 2020(7): 51-54.

[3] Zhou ZG. Causes and preventive measures of concrete cracks in railroad bridge piers[J]. Engineering Technology Research, 2020, 5(13): 174-175. 